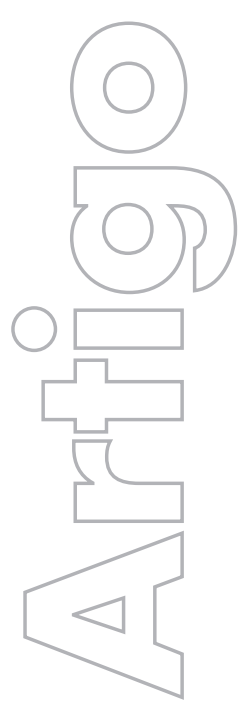

revista

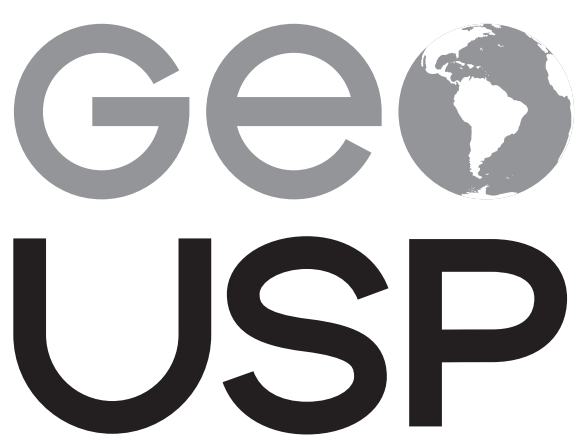

espaço e tempo

Volume $20 \cdot n^{\circ} 2(2016)$

ISSN 2179-0892

\section{Governança para o}

desenvolvimento territorial: da concepção à ação - o caso do programa Pará Rural

Sérgio Cardoso de Moraes UFPA

Milvio da Silva Ribeiro FATEFIG

p. $312-329$

Como citar este artigo:

MORAES, S. C.; RIBEIRO, M. S. Governança para o desenvolvimento territorial: da concepção à ação - o caso do programa Pará Rural. Geousp - Espaço e Tempo (Online), v. 20, n. 2, p. 312-329, mês. 2016. ISSN 2179-0892.

Disponível em: <http://www.revistas.usp.br/geousp/issue/ view/6465>. doi: http://dx.doi.org/10.11606/issn.2179-0892. geousp.2014.84539.

\section{(c) $(1) \circledast$}

Este artigo está licenciado sob a Creative Commons Attribution 4.0 License. 


\title{
Governança para o desenvolvimento territorial: da concepção à ação - o caso do programa Pará Rural
}

\section{Resumo}

artigo analisa a concepção e as ações de uma política pública do governo do estado do Pará (GEP) que visava promover desenvolvimento territorial: o Programa de Redução da Pobreza e Gestão dos Recursos Naturais do Pará (Pará Rural). A ideia era reduzir a pobreza dos entes rurais pobres com recursos de um acordo de empréstimo entre o Banco Mundial e o GEP. No entanto, o Pará Rural investiu em projetos produtivos sem ordenar o território, tendo desprezado processos de governança territorial que faziam parte de seus instrumentos e aplicado a política pública sem considerar as pessoas ou o ambiente para os quais ela foi projetada, como resultado de interesses antes de governos que do Estado.

Palavras-chave: Pará Rural. Governança. Ordenamento territorial. Investimento produtivo. Redução da pobreza.

\section{Governance for territorial development: From conception to action - The case of Para Rural Program}

\begin{abstract}
It is to analyze the proposal of a public policy of Para State Government (GEP), as its design and actions, presents towards territorial development. In rural areas the Amazon of Para, the GEP has designed a public policy that aims to reduce poverty in poor rural ones. With loan agreement of resources between GEP and World Bank, the Para Rural Program, investing in productive projects without ordering the territory, having despised territorial governance processes that were one of his instruments, in which public policy is carried out in violation of importance of people and the environment which, projecting the policy, resulting interests of governments than of State.
\end{abstract}

Keywords: Rural Para. Governance. Land use. Productive investment. Poverty reduction. 


\section{Introdução}

O Programa de Redução da Pobreza e Gestão dos Recursos Naturais do Pará (Pará Rural), cofinanciado pelo governo do estado do Pará (GEP) e pelo Banco Interamericano de Reconstrução e Desenvolvimento (Bird), ' foi criado pela Assembleia Legislativa do Estado do Pará (Pará, 2005). Integrando-se à Secretaria Especial de Estado de Desenvolvimento Econômico e Incentivo à Produção (Sedip-PA), tem o objetivo de reduzir a pobreza ${ }^{2}$ de pessoas que estejam na faixa de rendimentos estipulada pelo Estado ou abaixo dela.

Observam-se como lócus de pesquisa, além do Pará Rural, os municípios de Santa Bárbara do Pará e Igarapé-Açu, onde foram criados Fóruns de Desenvolvimento Municipal (FDM). A intenção de processos de governança que pretende o Pará Rural não se restringe ao público rural e ao programa, mas também às entidades reconhecidas como parcerias, estas com interesse em ordenar o território rural em termos ambiental e fundiário.

Desta feita, partimos da ideia de território, tanto no sentido de território normativo, em que incidi a ação, assim como, no sentido que encontramos em Santos e Silveira (2001) com a concepção de que o território é entendido como a extensão de apropriação e seu uso. E, ainda na ideia de que o "território é uma porção geográfica que coincide com a extensão espacial da jurisdição de um governo [...] uma conexão de ideal entre o espaço e política" (Gottmann 2012, p. 523). O território, como geração de conteúdos por indivíduos organizados segundo seus próprios objetivos, que se consolidam como fruto de repartição e de organização, portanto, um conceito político e geográfico.

Tratando-se de um processo que exige relevante capital social, ou "capital territorial, ou seja, os recursos ligados aos territórios, convertendo aqueles que são genéricos em específicos, resultando numa das mais importantes estratégias de desenvolvimento territorial" (Dallabrida; Marchesan, 2013, p. 209).

Trata-se de uma maneira de ressignificação da sociedade civil, de suas potencialidades, seu saber e sua territorialidade em situações concretas, dando significado territorial para suas ações como possibilidade de desenvolvimento rural.

Nossa problemática de pesquisa deveu-se à observação de que o programa como política de Estado se conectaria com os municípios através de processos de governança por meio de FDM. Mas, independentemente, os FDM atingiram mais 69 municípios, que, adicionados aos que constam com fóruns no período de 2008-2012, totalizam 73 municípios dos 144 do estado do Pará. Dessa constatação deriva a questão central da pesquisa: quais as possibilidades e dificuldades do estabelecimento de um processo de governança para o desenvolvimento?

A hipótese estruturadora da pesquisa é o fato de que o Pará Rural fez uma ambiciosa formulação de objetivos para o meio rural e, na prática, não os concretizou por diversos motivos tais como: o sentido da política, que, em vez de Estado, enveredou por uma política de governo; por outro lado, diante do frágil capital social da sociedade civil, que é instrumento necessário ao Pará Rural, pouco foi posto em prática para promover o desenvolvimento sustentável na perspectiva de governança territorial. Mesmo tendo eminente capital financeiro, o programa apoiou apenas 22 projetos de investimento produtivo (PIP), do total de 130 orçados.

1 Pelo Acordo de Empréstimo n. 7.414-BR, assinado em novembro de 2007 com o Banco Mundial.

2 Linha de Pobreza é um valor definido pelo governo do estado, correspondente, em julho de 2009, a R \$5.580,00/ano e sujeito a reavaliação periódica. 
A seguir o desdobramento do texto, em que se realiza a conceituação de governança, bem como se problematiza a ideia de desenvolvimento territorial, em seguida discutem-se território e território rural, inferindo território rural do Pará Rural e o sentido de desenvolvimento territorial rural para a Amazônia paraense. Por conseguinte, apresenta-se o programa Pará Rural como política: sua estrutura e concepção e a justificativa de escolha dos municípios Igarapé-Açu e Santa Bárbara do Pará, lócus da pesquisa, demonstrando também, a ação do Pará Rural: oportunidades, dificuldades e desafios e as considerações finais.

\section{Governança e desenvolvimento territorial}

Inicia-se por inferir a ideia de governança, encontrada em algumas literaturas, entre autores e instituições de maneiras distintas. Apresenta-se governança como "tomada de decisão relativamente horizontal, em oposição ao estilo mais hierárquico do governo tradicional" (Dallabrida, 2006, p. 5). Isto é, um instrumento com a "capacidade de fazer coisas sem a competência legal para ordenar que elas sejam feitas" (Czempiel, 2000, p. 335).

A palavra governance ressurge em documentos do Banco Mundial (BM) na década de 1980, referindo-se à capacidade financeira e administrativa do Estado. Para tornar efetivas as ações de governo na implementação de políticas, consecução de metas coletivas para otimizar, gerir recursos econômicos e sociais. Para dirigir capacidade governativa, como papel da política do BM para a política de desenvolvimento (Graña, 2005; Diniz, 1995; Dallabrida, 2006; Abdala, 2007).

Para Graña (2005, p. 4), "a 'governança' sugere explorar um modo de gerenciamento de gestão que se harmoniza com os novos tempos. A transformação da noção transpareceu em inovadora estrutura social e uma mudança do centro de gravidade da ação pública, e não um simples giro semântico". Conforme o mesmo autor, a ideia de boa governança nasce fortemente associada às políticas de desenvolvimento do mundo pós-colonial, onde o BM está interessado na legitimidade da participação dos cidadãos nas mudanças. E a adoção desse critério operacional era, para a instituição, uma maneira de aceitar que eles não podem ser considerados puramente técnicos, de "eficiência econômica" neutra, independentes de comportamento social e humano.

A governança pode ser compreendida como a totalidade das diversas maneiras pelas quais os indivíduos e as instituições, públicas e privadas, administram seus problemas comuns. A esse respeito não só as instituições e regimes formais autorizados em impor obediência, mas também acordos informais que atendam aos interesses das pessoas e das instituições (COMISSÃO SOBRE GOVERNANÇA GLOBAL, 1996).

Por esse viés, entende-se também que a governança refere-se à organização e à ação pública, capturando uma das maiores tendências, conforme Mark Bevir (2011, p. 103), em que "a organização e a ação pública moveram-se da hierarquia e da burocracia para os mercados e as redes". Surgiu em grande parte devido a uma crise do Estado moderno, que originando austeridade fiscal, entre outras mazelas sociais e políticas. Nas quais o Estado não poderia mais atuar isoladamente, sobrecarregado de dívidas, num quadro em que a sociedade, especialmente, eleitores demandam mais transparências, com líderes decididos (Bevir, 2011). 
Concernente a desenvolvimento territorial sustentável, busca-se problematizar como tema, fazendo-se a pergunta: qual o desenvolvimento que se tem pretendido para Amazônia, em espacial a Paraense? Sendo o desenvolvimento territorial sustentável o objetivo do Pará Rural, são compreensíveis as condições sob as quais se visa o desenvolvimento, que assim se constitui um conceito de nosso interesse.

O Pará Rural tem sua concepção influenciada pelo BM, que se vincula a ideia cerne redução da pobreza. Compreende o ordenamento territorial e ambiental, para uma possibilidade de desenvolvimento sustentável.

Isso poder decorrer dos recursos do território, mais o modo de estabelecimento de um determinado grupo, da organização, da localização das atividades e do aprendizado coletivo. Assim, o desenvolvimento territorial, longe de estar apenas vinculado à ideia da questão econômica. Vê-se o desenvolvimento no discurso de vários agentes políticos, instituições públicas e privadas; nesse caso, do GEP, do Pará Rural e de associações rurais, estas últimas visando recursos provenientes do BM via Pará Rural. Nessa perspectiva, o desenvolvimento territorial está posto como construção participativa, reconhecendo-se diferentes sujeitos, os distintos interesses, os anseios, os sonhos, as necessidades dos tempos e os territórios, as temporalidades, as territorialidades e a conquista de autonomia.

Destacando-se a importância da sociedade civil e sua participação no processo de construção e gestão do desenvolvimento territorial na sua relação com o Estado, Sérgio Boisier (2011) infere que a década de 1990 é o marco histórico que indica um novo estilo de governar, no qual se retornam os valores da democracia, como "um paradigma cognitivo útil para a gestão e o desenvolvimento territorial [com] necessidade de acumulação de conhecimento que permite a sociedade elaborar sua estratégia de desenvolvimento" (Boisier, 2011, p. 63).

Sobre a abordagem territorial, o pacto territorial concernente e as estratégias públicas e privadas, afirma Brandão (2011, p. 121): "as virtualidades do território como arena e campo catalisador e de possível confluência de projetos, que pode e deve assumir toda a conflituidade inexorável e necessária à adequada pactuação social pelo desenvolvimento". Seria uma possibilidade de abandonar atitudes acomodadas, institucionalizar o envolvimento e promover o diálogo e a negociação pactuada de interesses, buscando criar elementos políticos que reduzam incertezas no território.

\section{Território e território rural}

A reflexão a seguir busca contribuir para a análise de território e desenvolvimento territorial na perspectiva da governança a promover desenvolvimento territorial sustentável no âmbito do Pará Rural. Para isso, de início, concebe-se que, "nada considerado essencial hoje se faz no mundo que não seja a partir do conhecimento do que é o território. $\bigcirc$ território é o lugar em que desemboca todas as ações, todas as paixões, todas as forças, todas as fraquezas" (Santos; Silveira, 2001, p. 13).

A partir da compreensão do território como espaço de relações de poder, sociais e, logo, ganhando o sentido de movimento, é possível perceber os entraves que justifiquem a expansão do que podemos chamar de abordagem territorial. De acordo com Raffestin (1993), é no território que se consolidam fatores físicos, humanos, econômicos, políticos e sociais, e o autor aponta ainda a multiplicidade de atores. 
Fernandes (2004, p. 28) evoca que "el pensamiento consensual busca convencer de que el desarrollo territorial tiene el mercado como esencia”. Assim, diz Montenegro Gómez (2006, p. 31): "o meio rural é 'reabilitado' como lugar dinâmico, susceptível de promover um desenvolvimento de características particulares, porém com possibilidades de integrar-se plenamente, na dinâmica produtiva da sociedade". Vejamos como se comportam as proposições de desenvolvimento para a Amazônia. A seguir ideias de território na Amazônia paraense.

\section{Território rural e Pará Rural}

Iniciemos por mencionar Oliveira (2011, p. 55) que ao tratar do tema território rural, ao referir-se ao II Plano Nacional de Reforma Agrária, afirma que deste pouco se conseguiu realizar, no entanto, o governo federal encaminha um III Plano, mas com caráter, isto sim, de uma contra-reforma agrária brasileira. Em sua inferência crítica chama atenção para o fato de que o Il plano mencionado acima terminou em 2006, e o governo do PT tinha implantado apenas 149.490 assentamentos novos, ficando a diferença (231.929) para regularização, reordenação e reassentamento fundiários. Justifica sua afirmação de contrarreforma agrária da seguinte forma:

Até 2009, o governo do PT assentou de fato pouco mais de 197 mil famílias, embora o ufanismo do Incra anuncie que assentou 573 mil famílias. $\bigcirc$ segundo mandato, por sua vez, transcorreu sem que fosse elaborado o III Plano Nacional de Reforma Agrária, como manda a legislação em vigor, e, ao contrário, implantou-se a política de contrarreforma agrária para a expansão do agronegócio (Oliveira, 2011, p. 55, grifo do original).

O Pará Rural não foge à lógica descrita Oliveira (2011), pois os territórios rurais dos municípios paraenses estudados Santa Bárbara do Pará e Igarapé-Açu refletem a ausência do Estado para ordenar e regularizar, assim apenas consta em planejamento à distância, criou enorme anseio a população rural, sendo uma ação política nunca vista, que trazia em si o sentido de estabelecimento de um marco institucional - o Pará Rural, para uma prática, em que suas formulações apresentavam-se como vantajosas e perspicazes fundadas na ideia de sustentabilidade econômica, social e ambiental.

O ordenamento fundiário e ambiental que era necessário para o empreendimento do Pará Rural como ponto de partida para o desenvolvimento, não é óbvio a partir do próprio programa. Tem-se sim, uma forma de uso das áreas nos municípios ao ritmo das ocupações das terras devolutas em sucessivas formas de apropriação e usos dos recursos sem a presença do Estado como legitimador e organizador do território.

Está claro que se está diante de um alinhamento do Pará Rural que segue uma trajetória política de reforma agrária em que 2010 foi um ano atípico no processo de luta pela terra no Brasil (Oliveira, 2011), pois marcou o fim de dois mandatos de Luís Inácio Lula da Silva. $\bigcirc$ autor elucidou as características diferentes no que se refere à luta pela reforma agrária e pela democratização do acesso à terra no país. O primeiro mandato foi repleto de esperança na realização da reforma agrária.

Esperança que foi desaparecendo com o não cumprimento das metas [...] Era a não reforma agrária, ou melhor, a reforma agrária que o agronegócio queria. [...] não fazê-la nas áreas de domínio do agronegócio e, fazê-la apenas nas áreas onde ela 
pudesse "ajudar" o agronegócio. No segundo mandato, [...] o início da contrarreforma agrária acoplada à expansão do agronegócio no Brasil (Oliveira, 2011, p. 55. grifos do original).

Fazendo analogia com a expansão do agronegócio, cuja análise não cabe aqui, compreende-se que o caráter da política de ordenamento territorial do estado a partir do Pará Rural, segue uma lógica praticada pela política brasileira referente à questão do ordenamento do território.

que se assemelha a isso é constatado no Zoneamento Econômico Ecológico (ZEE) do Pará Rural quando apresenta as áreas genericamente consideradas aptas para a agricultura. Porém, as terras para agricultura familiar coincidem com as áreas de várzeas e das ilhas, não apropriadas para a agricultura familiar. Enquanto áreas propícias à agricultura familiar são zoneadas para a expansão das monoculturas como, por exemplo, de dendê, no caso da microrregião de Tomé-Açu -, transcorre um balizamento institucional do Estado que favorece as monoculturas e o grande capital, imobilizando a agricultura familiar e especialmente o camponês.

Analisando-se ZEE do Pará Rural sobre as terras com aptidão agrícola, considerando-se as de classe de terras boa para agricultura, elas representam a maior extensão na mesorregião nordeste paraense. $\bigcirc$ Pará Rural visa reduzir a pobreza dos entes rurais no estado do Pará atendendo famílias carentes, as que o programa considera agricultores familiares. Contudo, as terras apresentadas na classe de aptidão boa, para agricultura familiar, se incidem nas áreas de várzea e nas ilhas do estado do Pará. Desse modo, para quem é o Zoneamento?

A regularização fundiária como requisito para atingir os objetivos do Pará Rural forjou questões celebradas entre o GEP e o BM:

[...] a criação de um formulário de "título provisório" como um próximo passo para o registro no Cadastro Ambiental Rural (CAR). Também foram mencionadas instruções legais existentes que criaram um caminho mais simples e efetivo para regularização incluindo georeferenciamento de lotes, mas que não está sendo implementado atualmente (Pará Rural, 2012, p. 30, grifos nossos).

É possível perceber uma ineficácia contundente em termos de regularização fundiária, e se apresentam como saída para o problema as "titulações provisórias" e ainda a indução de "caminhos mais simples", estes não explicitados. Indicando consultorias a ser financiadas pelo Componente B2, com o objetivo de revisar procedimentos administrativos e leis existentes relativas à regularização da posse de terra e gestão fundiária para propor um sistema simplificado, afirma o BM:

Isso pode ser alcançado com um formulário intermediário de título baseado em um georeferenciamento menos preciso, mas que possibilitaria que mais famílias recebessem os benefícios em curto prazo. $\bigcirc$ vigente Marco de Avaliação para a Governança Fundiária no Brasil (que não faz parte do Pará Rural) apoiado pelo Banco inclui avaliação a nível estadual no Pará e também irá proporcionar uma oportunidade de discussão de políticas sobre regularização fundiária, assim como várias outras facetas da gestão fundiária no Estado (Pará Rural, 2012, p. 30, grifos nossos). 
Posto dessa maneira, estamos diante de uma proposição como mecanismo de saída para os entraves a o ordenamento fundiário no Estado, ao menos no que tange à dificuldade de o programa efetivar a regularização fundiária como parte do ordenamento territorial.

Por fim, a governança como instrumento do Pará Rural, para o desenvolvimento dos entes rurais pobres do meio rural, não ocorreu, nem entre o Estado e a sociedade civil, assim como, entre as entidades envolvidas como parceiras do Pará Rural. A seguir, considerações sobre a organização institucional do Pará Rural.

\section{O sentido de desenvolvimento territorial rural para a Amazônia paraense}

Partimos da análise de Ab'Saber (1992), para quem, desde a década de 1960, a Amazônia tem sido apresentada ao mundo ocidental como uma região uniforme e monótona, pouco compartimentada e sem diversidade fisiográfica ou ecológica. Enfim, um espaço sem gente e sem história, passível de qualquer manipulação por meio de planejamentos feitos à distância, ou sujeito a propostas de obras faraônicas, vinculadas a um falso conceito de desenvolvimento.

Inferindo-se a ideia ao Pará Rural, tem-se uma importante provocação de crítica, nas ideias: "se é possível decantar o que há de científico e o que há normativo, de ideológico, de meramente discursivo por detrás" da ideia de desenvolvimento (Favareto, 2006, p. 33).

A ideia de desenvolvimento pode equivaler a crescimento econômico, ou ser mais sofisticada e se aproximar de mito, ou servir como argumento ideológico falseador das reais intenções das políticas cunhadas a título de desenvolvimento. Mas há outras ideias associadas à palavra desenvolvimento. Por exemplo, liberdade; se é liberdade que o desenvolvimento promove, então, há um argumento fundamental em favor da concentração nesse objetivo abrangente (Sen, 2000). lgualmente "o desenvolvimento requer que se removam as principais privações de liberdade: pobreza e tirania, carência de oportunidades econômicas e destituição social sistemática, negligência dos serviços públicos e intolerância ou interferência excessiva de Estados repressivos" (Sen, 2000, p. 18).

Nesses princípios de ideias, encontra-se no relatório do Banco Mundial (2008), o objetivo de se conseguir agendas agrícolas para o desenvolvimento, com a governança nos níveis local, nacional e global, mas com melhoria na sua concepção e empreendimento.

Em que pese o debate de pretenso desenvolvimento, o que se realça na Amazônia é o aparecimento de implicitudes das formulações das políticas públicas. Thomas A. Mitschein (2009) evoca o tema do desenvolvimento tratando do atraso histórico sob as ideias de desenvolvimento retardatário e o futuro incerto da Amazônia no século XXI. Referencia-se ele no "privilégio do atraso histórico", de Leon Trótski, entendido para uma acirrada corrida desenvolvimentista na qual se pode fazer com que os países atrasados alcancem, em tempo recorde, os mais avançados, e se mostre incompatível com a limitada capacidade de transporte (carrying capacity) da natureza.

Nos anos 1970, por meio da Superintendência de Desenvolvimento da Amazônia (Sudam) (Mitschein, 2009, p. 307), o governo federal começa a implantar um "modelo Amazônico de crescimento desequilibrado corrigido", porque favorecia os setores mineral, madeireiro, pecuário, pesqueiro empresarial, eletrotérmico e eletrolítico que, segundo seus idealizadores, detinham vantagem no âmbito da economia (inter)nacional. É "corrigido" pois previa intervenção do Estado para aliviar as polarizações socioespaciais em setores selecionados anteriormente. 
Porém, de acordo com Mia Couto (Martins, 2014), "a ideia de desenvolvimento nega a identidade dos povos [...] estamos retirando o núcleo central, o ambiente. E essa negação é a negação da identidade cultural dos povos que foram expropriados". Logo, temos o sentido de que as políticas não têm sido eficientes no sentido de desenvolvimento sustentável dos povos da Amazônia.

A seguir se demonstram as ideias de desenvolvimento que se dirigem à Amazônia.

\section{Figura 1 - Discurso dos Planos de Desenvolvimento (PDA) para a Amazônia}

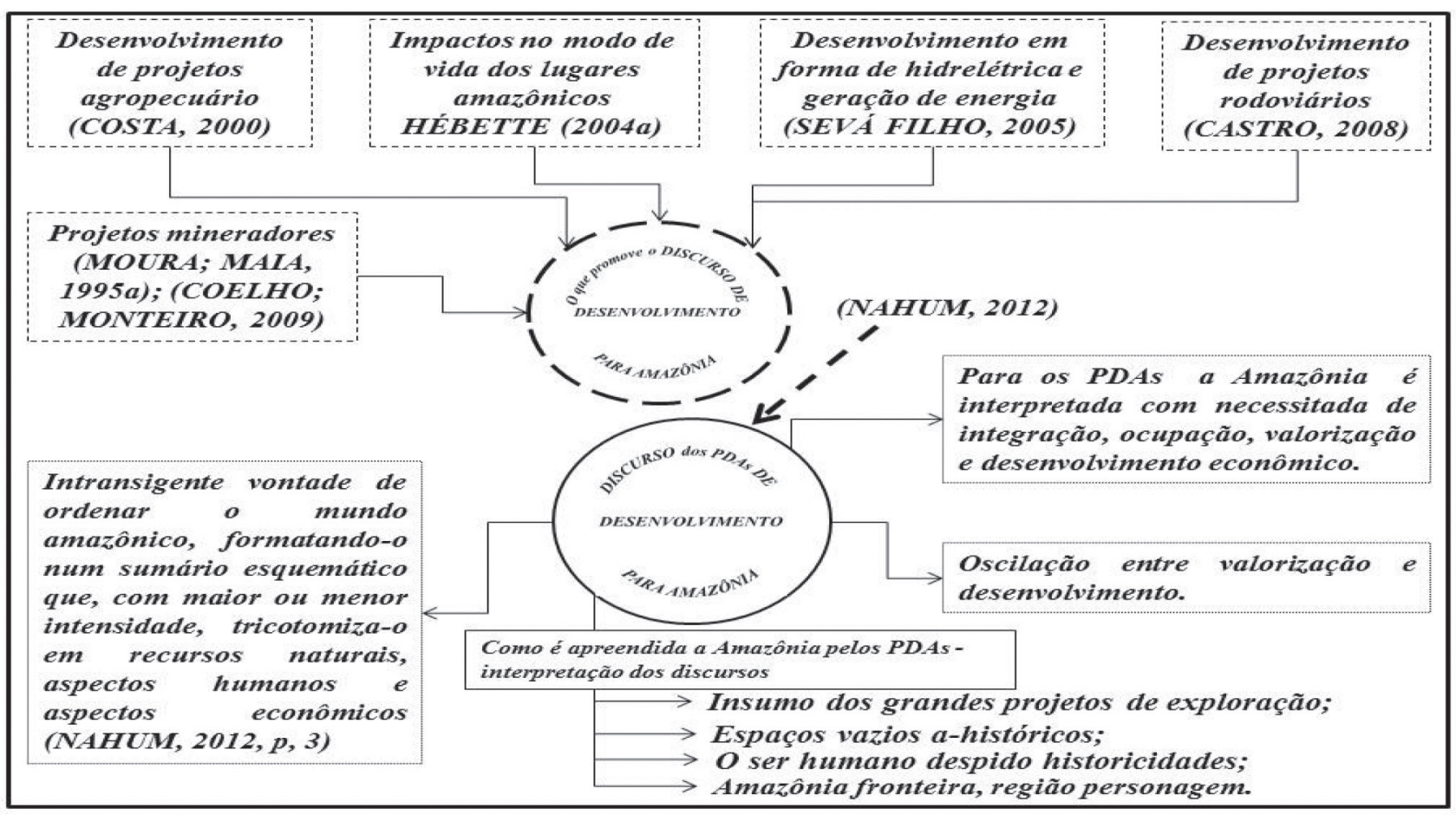

fonte: Nahum (1999). Organizado pelos autores.

A ideia de desenvolvimento rural pretendida pelo GEP por meio do Pará Rural reforça a tese de que o programa tenha objetivos ambiciosas que não se concretizaram por ter sido estabelecidos à distância do meio rural amazônico paraense.

Nahum (1999), interpreta a construção discursiva dos Planos de Desenvolvimento da Amazônia como forma de materializar seu poder de visão e divisão acerca do que desejavam que fosse a Amazônia. $\bigcirc$ autor destaca que "A Amazônia dos PDAs constitui palavras sérias, verbos, objetivos nacionais para a região" (Nahum, 1999, p. 10). Analisa que a função enunciativa dos discursos de desenvolvimento para a Amazônia não provém de um sujeito, nem da experiência originária, mas está relacionada a um referencial que faz aparecer o delineamento do que dá à frase seu sentido, a proposição de seu valor de verdade.

$\bigcirc$ discurso que aflora sobre a região Amazônica a encerra como espaço vazio, na qual não há homens, espaço que de tudo precisa, campo fértil para ordenar ações hábeis. Interpretado por Nahum (2012) como um discurso que silencia o homem da floresta da região. Nos PDA, reconhece-se a região para o capital como insumo dos grandes projetos de exploração, nas reservas naturais físicas, dos minerais disponíveis, como uma região natural. 
Nesse sentido, reafirma-se a tese em que o Pará Rural não tenha surtido efeitos positivos de desenvolvimento para o meio rural paraense, em função de ingerências políticas, dado ao fato das sucessivas trocas de grupos políticos no comando do GEP que como consequência impossibilita o estabelecimento de uma governança territorial, no sentido de um relacionamento sinérgico entre o púbico (Estado) e o privado (sociedade civil, associações rurais, cooperativas etc.).

\section{O Pará Rural como política: estrutura e concepção}

$\bigcirc$ foco desta sessão é apresentar o Pará Rural e seus objetivos. Trata-se de uma proposta político-estratégica do estado cuja área de abrangência geográfica é o ambiente rural do estado. $\bigcirc$ programa tem estrutura de funcionalidade e concepção, fundamentalmente, em seus elementos que o constitui como ferramenta para o desenvolvimento rural. Para tanto, nossas principais fontes de pesquisa foram os Módulos de Operação do Programa (MOP I e II), de 2009, e o MOP-2013.

Objetivo do Pará Rural é contribuir para o desenvolvimento rural sustentável do estado, estabelecendo-se como objetivo mais específico a redução da pobreza do meio rural paraense para gerar oportunidades de trabalho e renda para famílias que estejam na faixa de rendimentos estimada pelo Estado ou abaixo dela.

De acordo com o GEP (Pará, 2009a), o programa atua em duas frentes convergentes de ação: a primeira relativa ao aumento da renda e à melhoria das condições de vida de comunidades rurais pobres. A segunda direcionada ao fortalecimento e aprimoramento do processo de gestão fundiária e ambiental do Pará, mediante investimentos na melhoria da estrutura institucional responsável pelo ordenamento territorial.

A estrutura do Pará Rural é em forma de componentes (Quadro 1):

\section{Quadro 1 - Estrutura do programa Pará Rural}

\begin{tabular}{cl}
\hline componentes & \multicolumn{1}{c}{ questões de tratamento: } \\
\hline A & $\begin{array}{l}\text { Investimento Produtivo em Projeto de Desenvolvimento Local - PDL; Projeto } \\
\text { de Desenvolvimento Municipal- PDM }\end{array}$ \\
\hline B & $\begin{array}{l}\text { Ordenamento territorial, tendo como subcomponente B1, com a gestão Am- } \\
\text { biental e o subcomponente B2, a gestão fundiária; }\end{array}$ \\
\hline C & $\begin{array}{l}\text { Desenvolvimento de políticas, tendo no subcomponente Cl a avaliação am- } \\
\text { biental estratégica, no subcomponente C2, estudos e movimentos de Pobreza } \\
\text { e no subcomponente C3, destinado a outros estudos; }\end{array}$ \\
\hline D & $\begin{array}{l}\text { Gerenciamento do programa, dividido no subcomponente D 1, administração e } \\
\text { gerenciamento, subcomponente D2, relacionado a comunicação e o subcom- } \\
\text { ponente D3, ao monitoramento e avaliação das ações do programa. }\end{array}$ \\
\hline
\end{tabular}


Um desafio do programa é superar de vez a dependência histórica da economia paraense em relação à exploração ${ }^{3}$ de matérias-primas renováveis e não renováveis. Para tanto, gerar emprego e renda, é seu objetivo a partir das potencialidades das diferentes regiões do Pará, busca ordenar o território com governança e consolidar um novo modelo de "desenvolvimento socioeconômico, pautado no conceito de desenvolvimento econômico ambientalmente sustentável [...] estruturando seu sistema de ordenamento territorial" (Pará, 2009b, p. 79). A seguir os processos de governanças:

\section{Figura 2 - Processos de governança e instituições envolvidas}

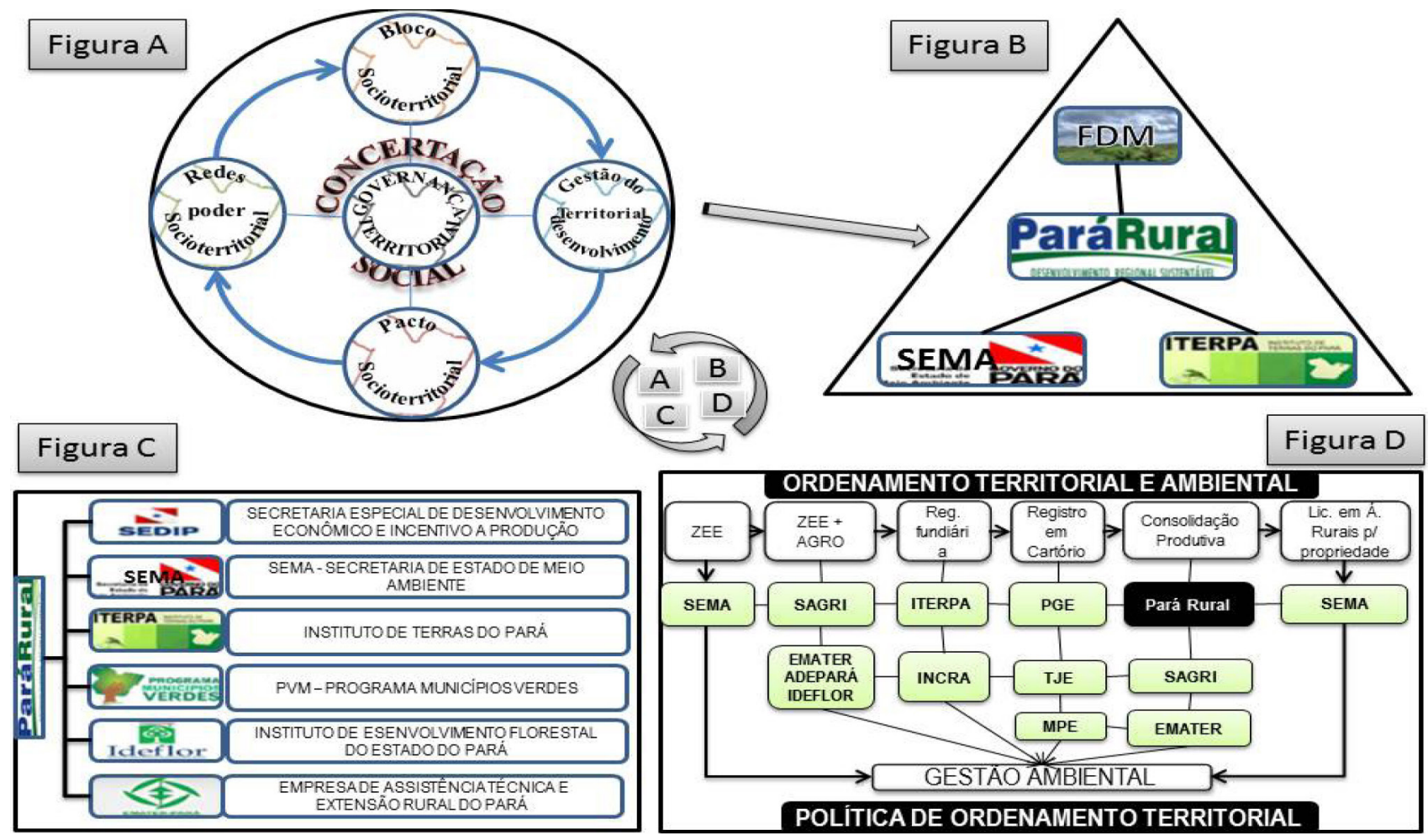

Fonte: Dallabrida (2006) e Pará (2009a, 2009b). Organizado pelos autores.

A Figura 2A sintetiza a concepção inicial do programa. A Figura 2B mostra a conexão do Pará Rural com os fóruns e sua projeção de funcionamento sinérgico; é a ideia de governança na dinâmica que poderiam realizar os atores nos FDM, tendo as ações do Instituto de Terras do Pará (Iterpa) e da Secretaria de Estado de Meio Ambiente-Pará (Sema) convergido para o desenvolvimento rural.

Na Figura 2C, o conjunto de parceiros que congregam esforços no âmbito do programa, e a Figura 2D apresenta institucionalmente as ações do componente B com a Política Estadual de Ordenamento Territorial (Peot) para atingir as metas expressas na ação fundiária no Pará.

3 Como esclarece Costa (2009), trata-se de um extrativismo de aniquilamento, pois atende a um paradigma agropecuário, em que as soluções tecnológicas supõem transformação profunda da natureza originária (agropecuária) e se distingue por ser um trajetória (patronal T4) conduzida por agentes patronais, marcada por uso extensivo do solo, homogeneização da paisagem (alto impacto na biodiversidade) e formação intensa de dejetos: na forma de emissões poluentes (pela queima da floresta na formação de plantações e pastagens) e na forma de áreas degradada. 


\begin{tabular}{lll}
\hline \multicolumn{1}{c}{ descrição } & $\begin{array}{c}\text { área } \\
\text { (milhões de ha) }\end{array}$ & \multicolumn{1}{c}{ observação } \\
\hline $\begin{array}{l}\text { Estimativa do Iterpa de existência de terras } \\
\text { estaduais devolutas }\end{array}$ & 25.000 .000 ha & Terras arrecadadas e não destinadas \\
\hline $\begin{array}{l}\text { Titulações expedidas pelo Iterpa desde sua cria- } \\
\text { ção, em outubro de 1975, até 2005 (31 anos) }\end{array}$ & 4.100 .000 ha & $\begin{array}{l}\text { Esses sem o critério de coordenadas } \\
\text { geodésicas }\end{array}$ \\
\hline $\begin{array}{l}\text { Meta de 2 anos, em termos de regularização } \\
\text { Por meio do Programa Terra Legal - Soma-se a } \\
\text { esse esforço do GEP a ação do governo federal }\end{array}$ & 2.250 .000 ha* & $\begin{array}{l}\text { Visa regularizar mais de } 90 \text { mil pos- } \\
\text { ses em áreas federais no estado }\end{array}$ \\
\hline * Se as áreas a ser regularizadas como posse em áreas federais são de lotes para agricultura familiar de 25 ha cada. \\
\hline
\end{tabular}

fonte: GEP (Pará, 2009a, 2009b). Organizado pelos autores.

Essas metas estabelecidas se referem às áreas novas, e não constam regularização ou delimitação de unidades de conservação (UC) ou áreas quilombolas já criadas, mas ainda não regularizadas de fato, para efeito de arrecadação, destinação e demarcação física dos perímetros que fará o governo para gerir os processos demanda participação da sociedade civil. Para tanto, são imprescindíveis os investimentos produtivos e os FDM. No entanto, nos municípios estudados, as metas não foram atingidas.

\section{Igarapé-Açu e Santa Bárbara do Pará - lócus da pesquisa}

Ao longo do artigo, menciona-se a Amazônia paraense porque o Pará Rural foi elaborado para atender todo o estado do Pará, no entanto, escolhemos estudar dois municípios paraenses onde já estavam adiantados os processos de uma possível governança, inclusive com PIP em andamento: Igarapé-Açu e Santa Bárbara do Pará. Igarapé-Açu, por exemplo, foi criado nele o primeiro FDM, reconhecido como a melhor experiência do programa, posteriormente, em Santa Bárbara, que não se alinhou às concepções de governança. A pesquisa concluiu que, de fato, estavam em andamento os processos de ordenamento do território, nas perspectivas fundiária e ambiental em Igarapé-Açu, município onde se encontraram associações organizadas para captar recursos do programa e colocar em prática seus empreendimentos tais como a Associação de Produção de Mel Industrializado de Igarapé-Açu (Amiga) e a Associação Rural de Vila União (Arvu), que produz hortaliças. Em Santa Bárbara do Pará, não se encontrou organizado um fórum, mesmo sem as concepções mais formais de governança, mas há uma associação com um empreendimento agroflorestal. No entanto, mesmo com as terras do sistema agroflorestal em litígio e contra princípios de ordem legal, foi financiada pelo Pará Rural, que se esquecera dos aspectos fundiário e ambiental do processo de ordenamento do território. 


\section{Figura 3 - Localização dos municípios pesquisados}
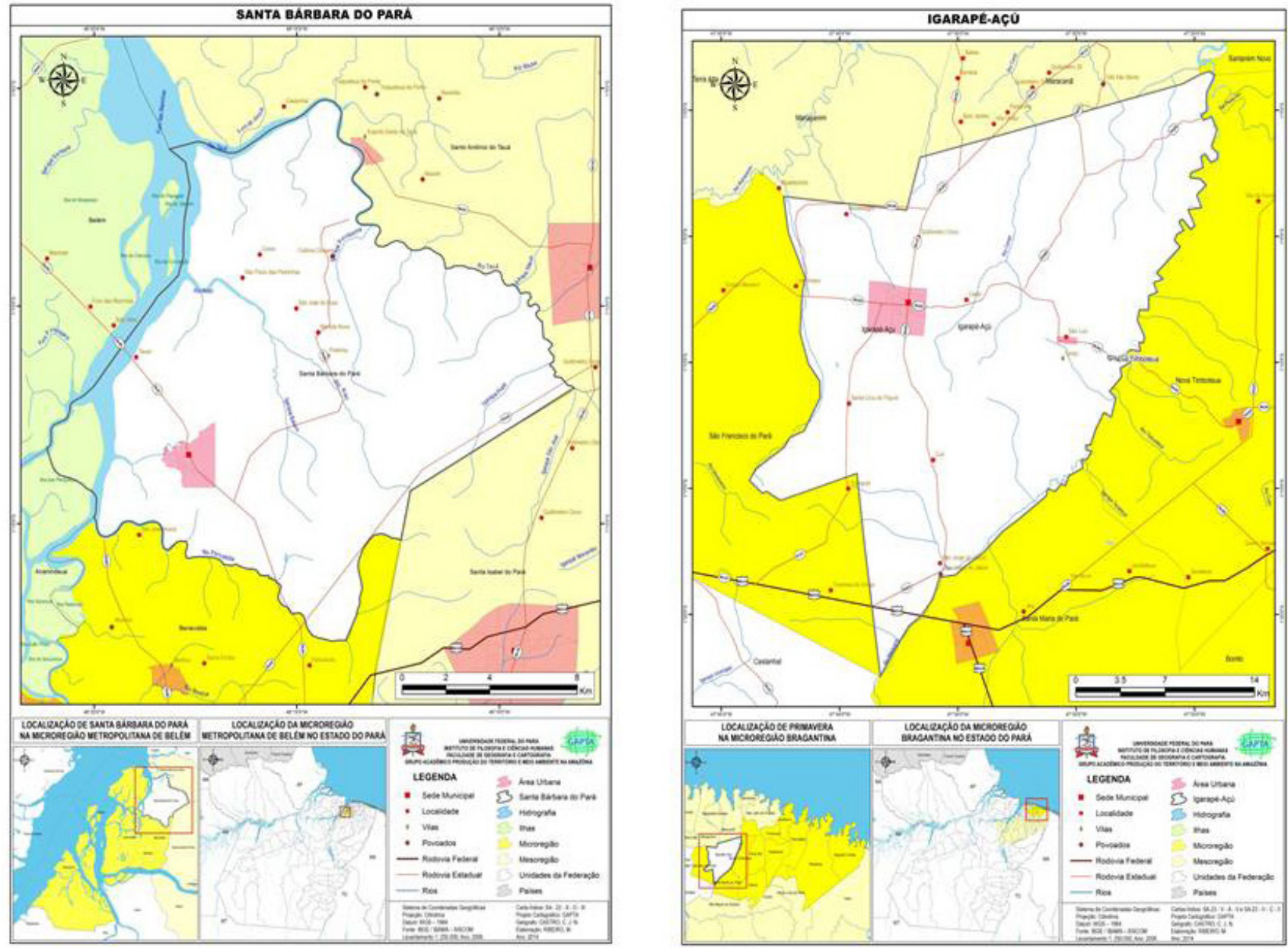

Inicialmente, os fóruns eram compreendidos como instâncias consideradas pelo Pará Rural para o exercício da governança nas quais a sociedade civil, o Estado e outras instituições como o BM se constituiriam em territórios locais, relacionando-se com outros espaços (Haesbaert, 2005), territórios-redes cujas fronteiras estão sempre em negociação nas relações entre os diferentes atores que ali se integram. Mas o programa passou a efetivar projeto de investimento produtivo em municípios que não têm fóruns.

\section{A ação do programa Pará Rural: oportunidades, dificuldades e desafios}

As oportunidades, dificuldades e desafios do programa, fazem-se presentes no contexto das ações com os entes municipais. As projeções de desenvolvimento do Pará Rural apresentou-se como uma oportunidade. Nas palavras de um líder comunitário, beneficiário de um PIP coletivo no município de Santa Bárbara do Pará, "oportunidade se faz com dinheiro", remetendo-se à oportunidade que o Pará Rural proporcionaria, que vai de 2008, quando é assinado o acordo de empréstimo de UU\$ 100 milhões de dólares, a dezembro de 2014, término do programa. Parece evidente que o principal recurso para o desenvolvimento que se propõe é mesmo o dinheiro. Desse montante, 60\% são oriundos do BM e 40\% dos cofres do estado do Pará. 
Uma das principais iniciativas:

Potencializar o aproveitamento das oportunidades locais de desenvolvimento, criando condições para o acesso de produtos e serviços ao mercado; aumentar o capital social da população rural, fortalecendo processos participativos de definição de prioridades, seleção, execução e manutenção de projetos; e, fortalecer as instituições do Estado, responsáveis pela gestão ambiental e fundiária (Pará, 2009a, p.15).

Compreende-se que é dentro desses objetivos estratégicos elaborados que se evidenciam as oportunidades de desenvolver o meio rural. No entanto, a oportunidade que se apresentou no período mencionado esteve mais na perspectiva do discurso do que na prática, apesar de que, isso não se apresenta como realidade em todos os espaços no qual o programa atua.

A função ideológica essencial do discurso do governo, sobretudo, o de mascarar, por procedimentos que não são evidentes. Um exemplo é o das ações projetadas, apenas vinte e dois projetos de investimentos constam em execução.

\section{Figura 4 - Cenário de PIP com e sem contrato junto ao Banpará}

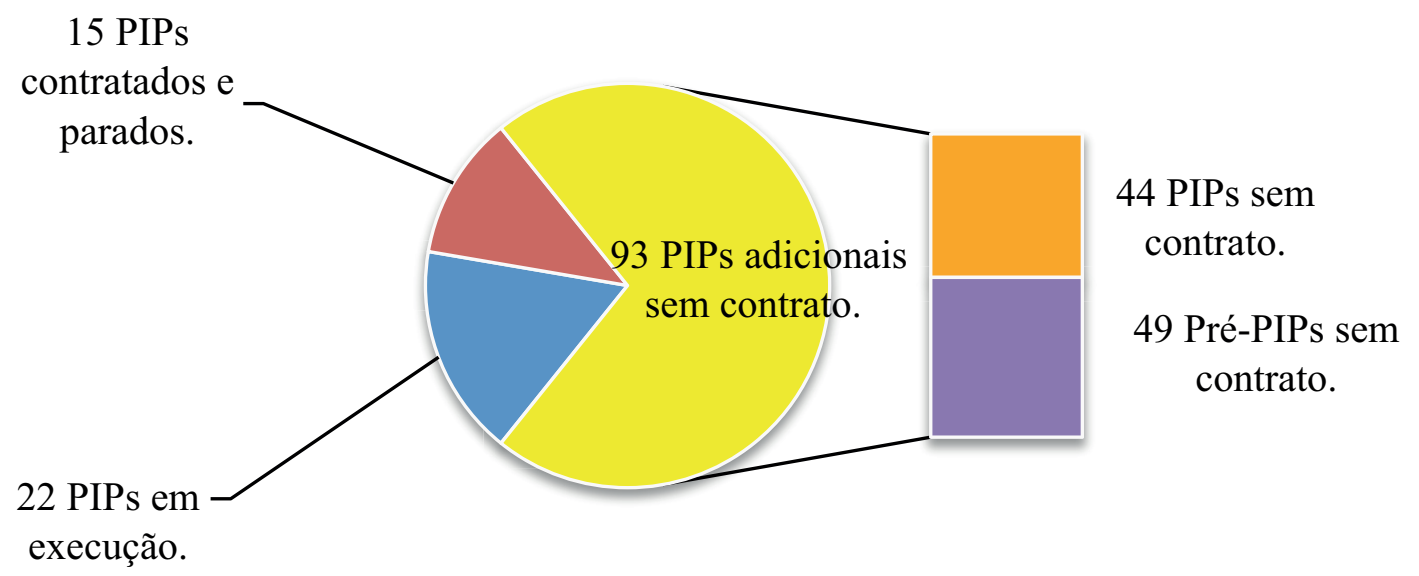

fonte: GEP (Pará, 2009a, 2009b). organização: Sérgio Cardoso de Moraes e Milvio da Silva Ribeiro.

Apresentamos como exemplo o PIP da Arvu, de Igarapé-Açu, onde as possibilidades de desenvolvimento sustentável são vistas como positivas pela associação, como confirma a colocação de um de seus membros: "Foi bom, o trabalho melhorou muito. Produzimos bastante hortaliças [mas pondera], no início". Mas, de acordo com outro entrevistado, "foi um desastre! Foi feita por meio do Ideasul [Instituto de Desenvolvimento da Amazônia Sustentável], que em nada nos ajudou".

Com relação ao PIP da Amiga, há aspectos que indicam governança, uma vez que a entidade realiza seus trabalhos conectando-se com instituições de ensino - Fazenda Escola de Igarapé-Açu (Feiga) e Universidade Federal Rural da Amazônia (Ufra) e capta técnica e capacitação para o empreendimento. Além disso, participa do FDM bimestralmente com a representação da presidência da associação. 
No entanto, analisando-se o quadro socioeconômico do município, a partir da fala de um ente municipal, "muitas pessoas estão esperando a vinda de Jesus com o maná do Céu". Essa referência se deve às várias formas de assistencialismo que foram concebidas na sociedade, a exemplo do Bolsa Família e Bolsa Jovem, que fazem com que muitas pessoas não queiram ter carteira assinada para não perder o direito ao programa.

Quanto ao PIP do Sistema Agroflorestal de Santa Bárbara do Pará, remonta a desafios como problemas de execução do que fora elaborado, que vão desde o atraso do projeto à desistência dos sócios do PIP, além do acesso às oportunidades, como nos relatou a agricultora J. M. L. B., secretária da Associação dos Trabalhadores Rurais do Assentamento Expedito Ribeiro (Atraer): "Olha, eu sou agricultura, e não é pela terra que não carrego debaixo da unha, sou agricultora porque lido com a terra, logo, eu não preciso me sujar de terra". Remetendo-nos às dificuldades da Atraer, interpelada algumas vezes por sua postura diferenciada para uma agricultora (seu eminente capital territorial), pois se mostrava desembaraçada diante das instituições pelo interesse de desenvolvimento para sua comunidade. Diante disso, considera-se que um(a) agricultor(a) não precisa ter as marcas da miséria da roça, do cabo da enxada, da foice, do facão ou de outro instrumento que caleje as mãos para ser do campo, camponês ou agricultor familiar.

\section{Considerações finais}

Para estas considerações finais, partimos do lócus de pesquisa: não apenas o programa em si, mas também os Projetos de Investimentos Produtivos nos municípios de Igarapé-Açu e Santa Bárbara do Pará nas associações Arvu, Amiga e Atraer.

Inicialmente, admitimos a hipótese de o Pará Rural não ter efetivado o desenvolvimento que planejou, em função de ingerências políticas e da sucessão dos grupos políticos que governaram o estado entre 2007 e 2014 e puseram a perder a possibilidade de um processo de governança territorial, ordenamento territorial do meio rural e desenvolvimento sustentável. Assim, a grande expectativa de desenvolvimento ficou restrita a uma fábula, e a perpetua-se a pobreza rural.

Salientamos a ideia de desenvolvimento territorial como processo de transformação, e o programa poderia ter reabilitado o rural como um lugar dinâmico, capaz de um desenvolvimento de características particulares. Mas, feitos à distância, os planos se referiram a um espaço vazio e não puderam atender ninguém.

Por exemplo, o desenvolvimento local ou territorial foram como simulacros de mudança, comprometendo-se a respeitar a heterogeneidade e promover desenvolvimento a partir dos recursos endógenos e com as características de um lugar determinado.

No decorrer da pesquisa, verificamos uma distância importante entre o que mostra e o que esconde o programa, entre o que promete e o que oferece e entre o que faz e o que alega fazer.

A força e a legitimidade da ideia de desenvolvimento parecem residir em articular discursos e práticas capazes de dissimular e até fazer desaparecer os erros, os fracassos e, enfim, a crua ineficácia das estratégias adotadas. 
De modo geral, observou-se a impraticabilidade da política de ordenamento, que dificultou à Sema e ao Iterpa ordenarem o território, condicionando-os às orientações do BM para "caminhos mais fáceis", e tendo resultado na elaboração do Cadastro Ambiental Rural pela Emater. Assim, consideramos o CAR um substituto do ordenamento para responder às exigências do BM.

O GEP transfigurou a política pública Pará Rural, que visava reduzir a pobreza, a mais uma falsa ideia de desenvolvimento sustentável, consagrando a negligência como base da hegemonia e do poder político. Ao fim e ao cabo, o centro do poder sabotou a ação coletiva, numa manobra para seus próprios fins, e não os da política de Estado.

Tendo implícita uma possibilidade de governança territorial, o Pará Rural poderia ter sido um instrumento para o desenvolvimento e concorrido para reduzir a pobreza, mas o desenvolvimento sustentável na perspectiva da boa governança depende da capacidade de mobilização dos atores locais e da definição de suas prioridades.

No município de Igarapé-Açu, os PIP estão em andamento: o de produção de hortaliças está fadado ao fracasso. Em trabalho de campo, identificaram-se indicadores como pouca assistência técnica e dificuldades na aquisição de insumos e de acesso ao mercado. Além disso, a identidade geográfica de uma produção orgânica da hortaliça aufere baixo lucro no mercado, o que condiciona a sustentabilidade comercial e arrefece o interesse dos agricultores de ampliar a produção.

Verificamos também que os PIP de Vila União - Igarapé-Açu e Atraer (Santa Bárbara do Pará) - não constam entre os 22 em execução, e talvez se deva a isso o atraso das etapas que faltam. Logo, os beneficiários do PIP contam apenas com a boa vontade do Pará Rural, sem as devidas prestações de serviços ou etapas para a consecução dos objetivos de desenvolvimento. Nas primeiras informações prestadas pelo programa, há muitas incertezas e ambiguidades e, na prática, não se identifica nos usos do povo o propagado desenvolvimento. Acreditamos que esse desencontro se deva ao fato de o programa ter sido planejado fora do território, sem escutar as vozes da pobreza do povo rural paraense. Ignoraram-se as pessoas do lugar, mas lhes tiraram sua autonomia com as ideias de uma governança territorial. Essa é uma expressão nova, cheia de intenções, que traz o discurso do desenvolvimento sustentável, mas como falsa ideia de desenvolvimento.

\section{Referências}

ABDALA, F. A. Governança global sobre florestas: o caso do programa piloto para proteção das florestas tropicais do Brasil (PPG7) - 1992-2006. Tese (Doutorado em Política Internacional e Comparada) - Instituto de Relações Internacionais, Universidade de Brasilia, Brasilia, 2007.

AB'SABER, A. N. Amazônia: proteção ecológica e desenvolvimento. São Paulo em Perspectiva, São Paulo, v. 6, n. 1, p. 112-126, 1992.

BANCO MUNDIAL. Relatório sobre o desenvolvimento mundial da agricultura para o desenvolvimento. Washington, DC, 2008. 
BEVIR, M. Governança democrática: uma genealogia. Revista de Sociologia e Política, Curitiba, v. 19, n. 39, p. 103-114, jun. 2011.

BOISIER, S. Sociedad civil, participación, conocimiento y gestión territorial. Mirando por el retrovisor: la década de los años noventa y el proceso de democratización en América Latina. In: DALLABRIDA, V. R. (Org.). Governança territorial e desenvolvimento: descentralização político-administrativa, estruturas subnacionais de gestão do desenvolvimento e capacidade estatais. Rio de Janeiro: Garamond, 2011. p. 53-72.

BRANDÃO, C. A. Descentralização enquanto modo de ordenamento espacial do poder e de reescalonamento territorial do Estado: Trajetória e desafios para o Brasil. In: DALLABRIDA, V. R. (Org.). Governança territorial e desenvolvimento: descentralização político-administrativa, estruturas subnacionais de gestão do desenvolvimento e capacidade estatais. Rio de Janeiro: Garamond, 2011. p. 115-135.

COMISSÃO SOBRE GOVERNANÇA GLOBAL. Nossa comunidade global: o relatório da comissão sobre governança global. Rio de Janeiro: Editora FGV, 1996.

COSTA, 2009

CZEMPIEL, E. O. Governança e democratização. In: ROSENAU, J. N.; CZEMPIEL, E. O. (Org.). Governança sem governo: ordem e transformação na política mundial. Trad. Sérgio Bath. Brasilia: Editora da UnB/São Paulo: Imprensa Oficial do Estado, 2000. p. 335-362.

DALLABRIDA, V. R. Governança territorial: a densidade institucional e o capital social no processo de gestão do desenvolvimento territorial. In: SEMINÁRIO INTERNACIONAL SOBRE DESENVOLVIMENTO REGIONAL, 3., 2006, Santa Cruz do Sul. Anais... Santa Cruz do Sul: Edunisc, 2006. v. 1. p. 1-19.

; MARCHESAN, J. Desenvolvimento na região do Contestado: reflexões sobre território, identidade territorial, recursos e ativos territoriais, indicação geográfica e desenvolvimento (sustentável). In: DALLABRIDA, V. R. Território, identidade territorial e desenvolvimento regional: reflexões sobre indicação geográfica e novas possibilidades de desenvolvimento com base em ativos com especificidade territorial. São Paulo: LiberArs, 2013. p. 195-232.

DINIZ, E. Governabilidade, democracia e reforma do Estado: os desafios da construção de uma nova ordem no Brasil dos anos 90. Dados - Revista de Ciências Sociais. Rio de Janeiro, v. 38, n. 3, p. 385-415, 1995.

FAVARETO, A. S. Paradigmas do desenvolvimento rural em questão: do agrário ao territorial. Tese (Doutorado em Ciência Ambiental) - Universidade de São Paulo, São Paulo, 2006.

FERNANDES, B. M. Cuestión agraria: conflictualidad y desarrollo territorial. In: SEMINARIOS EN EL LINCOLN CENTER INSTITUTE OF LAND POLICY Y EN HAVARD UNIVERSITY DEBATIENDO LA CUESTIÓN DEL ACCESO A LA TIERRA Y CONFLICTOS AGRARIOS EN BRASIL, 2004. 
GOTTMANN, J. A evolução do conceito de território. Agbcampinas - Boletim Campineiro de Geografia, Campinas, v. 2, n. 3, p. 523-545, 2012.

GRAÑA, F. Globalización, gobernanza y "Estado mínimo": pocas luces y muchas sombras. Polis [En línea], n. 12, 2005. Disponível em: <http://polis.revues.org/5563>. Acesso em: 8 nov. 2016.

HAESBAERT, R. Desterritorialização, multiterritorialidade e regionalização. In: OFICINA SOBRE A POLÍTICA NACIONAL DE ORDENAMENTOTERRITORIAL, 2003, Brasilia. Anais... Brasilia: Ministério da Integração Nacional, 2005. p. 15-29.

MARTINS, H. Ideia de desenvolvimento nega identidade dos povos, diz Mia Couto na Bienal. EBC Agência Brasil, 16 abr. 2014. Disponível em: <http://agenciabrasil.ebc.com. br/cultura/noticia/2014-04/ideia-de-desenvolvimento-nega-identidade-dos-povos-diz-mia-couto-na-bienal>. Acesso em: 25 abr. 2014.

MITSCHEIN, T. A. Atraso, desenvolvimento retardatário e o futuro incerto da Amazônia no século XXI. In: ROCHA, G. M.; MAGANHÃES, S. B.; TEISSERENC, P. Territórios de desenvolvimento e ações públicas. Belém: Edufpa, 2009. p. 291-318.

MONTENEGRO GÓMEZ, J. R. Desenvolvimento em (des)construção: narrativas escalares sobre desenvolvimento territorial rural. Tese (Doutorado em Geografia) - Faculdade de Ciências e Tecnologia, Universidade Estadual Paulista, Presidente Prudente, 2006.

NAHUM, J. S. Região e representação: a Amazônia nos planos de desenvolvimento. Biblio 3W - Revista Bibliográfica de Geografía y Ciencias Sociales [En línea], Barcelona: Universidad de Barcelona, v. XVII, n. 985, 25 jul. 2012. Disponível em: <http://www.ub.es/geocrit/b3w-985.htm>. Acesso em: 8 nov. 2016.

A Amazônia dos PDAs: uma palavra mágica? Dissertação (Mestrado em Desenvolvimento Sustentável do Trópico Úmido - PDTU) - Coordenação de Aperfeiçoamento de Pessoal de Nível Superior, Universidade Federal do Pará, Belém, 1999.

OLIVEIRA, A. U. Os posseiros voltam a assumir o protagonismo de luta camponesa pela terra no Brasil. In: CANUTO, A.; LUZ, C. R. S.; WICHINIESKI, I. Conflito no Campo 2010. Goiânia: CPT, 2011. p. 55-62.

PARÁ. Zoneamento ecológico-econômico das zonas leste e calha norte do estado do Pará. Editores técnicos: Carmen Roseli Caldas Menezes, Marcilio de Abreu Monteiro e Igor Maurício Freitas Galvão. Belém, PA: Núcleo de Gerenciamento do Programa Pará Rural, 2010. 3 v.

. Concepção e implementação do programa de redução da pobreza e gestão dos recursos naturais do Pará (Pará Rural). Manual Operacional, 2009a. v. 1.

Programa de redução da pobreza e gestão dos recursos naturais do Pará (Pará Rural).

Manual Operacional, 2009b. v. 2: anexos. 
ASSEMBLEIA LEGISLATIVA. Lei n. 6.796, de 16 de novembro de 2005. Dispõe sobre a alteração na Lei n. 6.607, de 26 de dezembro de 2003, que institui o Plano Plurianual 2004/2007. Disponível em: <http://www.pge.pa.gov.br/sites/default/files/ lo6796.pdf>. Acesso em: 8 nov. 2016.

PARÁ RURAL. Loan 7414-BR: missão de apoio à implementação e supervisão - ajuda Memória, Belém, p. 5-6, 22 out./1 nov. 2012.

RAFFESTIN, C. Por uma geografia do poder. 8. ed. São Paulo: Ática, 1993.

SANTOS, M.; SILVEIRA, M. L. O Brasil: território e sociedade no início do século XXI. Rio de Janeiro: Record, 2001.

SEN, A. K. Desenvolvimento como liberdade. Trad. Laura Teixeira Motta; rev. técnica Ricardo Doniselli Mendes. São Paulo: Campanhia das Letras, 2000.

SILVEIRA, M. L. Território usado: dinâmicas de especialização, dinâmicas de diversida-

de. Ciência Geográfica, Bauru, v. XV, n. 1, p. 4-12, jan./dez. 2011. 